\title{
GROWING WITH THE FLOW: ON THE MAINTENANCE AND MALLEABILITY OF COLONY FORM IN THE HYDROID HYDRACTINIA
}

\author{
Steven R. Dudgeon ${ }^{1, *}$ and Leo W. Buss ${ }^{1,2,+}$ \\ ${ }^{1}$ Department of Biology, Yale University, New Haven, Connecticut $06511 ;{ }^{2}$ Department of Geology \\ and Geophysics, Osborn Memorial Laboratories, Yale University, New Haven, Connecticut 06511
}

Submitted September 9, 1994; Revised August 8, 1995; Accepted August 31, 1995

\begin{abstract}
The extent of genetic predetermination and hence the limits of developmental plasticity of phenotypes are largely unknown. In this context, we address a prominent theme of morphological variation in clonal organisms: the relative investment in vascular versus ramet tissue. The colonial hydroid Hydractinia is characterized by colonies with widely spaced polyps and long stolonal connections (runners) and colonies with closely packed polyps and short stolonal connections (sheets). Surgical manipulations of gastrovascular architecture were used to alter flow patterns with in developing runner and sheet colonies, and subsequent morphological development of colonies was assessed. Reducing within-colony variation in patterns of gastrovascular flow of runner colonies resulted in a lower rate of production of peripheral stolons and a sheet-type morphology. Experimentally increased variation in flow patterns with in sheet colonies resulted in the development of peripheral stolons-hence, the initiation of a runnerlike growth trajectory. In both experiments, control colonies, in which stolonal architecture was not manipulated, maintained the runner or sheet morphology characteristic of their respective clones. The results imply that for this clonal species, morphological differences between genotypes can be controlled by changing gene expression in response to the local physiological conditions.
\end{abstract}

Phenotypic plasticity is the degree to which the expression of a genotype varies in response to environmental change. It is important in evolution because organisms with great phenotypic plasticity display different phenotypes in different environments. Moreover, those organisms will respond to the same selective pressures differently in different environments (Thompson 1991; Stearns 1992). Most previous studies on the evolutionary significance of plasticity have focused on unitary organisms with age-specific demographic schedules. Such studies have dealt with the adaptive significance of reaction norms and genotype $\times$ environment interactions of morphology and life-history traits (Stearns and Koella 1986; Gebhardt and Stearns 1988; Sinervo 1990). Yet phenotypic plasticity is widespread among, and indeed characteristic of, clonal organisms (Harvell 1994), and it is among these organisms that studies of plasticity are likely to be most fruitful.

Previous studies across a range of clonal organisms have shown that environmental factors (e.g., nutrient availability in slime molds; photoperiod in many

* E-mail: naknowl@yalevm.cis.yale.edu.

†E-mail: lwbuss@yalevm.cis.yale.edu. 
plants and algae; crowding in some colonial invertebrates) influence morphogenesis, growth rates, and the timing of reproduction and activate defense mechanisms (Dring 1984; Lüning 1986; Harvell and Grosberg 1988; Bozzaro 1992; Harvell 1992). But neither the limits of plasticity nor the physiological processes responsible for it are well understood. Such studies will enhance our understanding of phenotypic plasticity as a key determinant underlying the evolutionary potential of morphological and correlated life-history traits.

Aside from showing great plasticity, clonal taxa are one of the few cases where the mechanistic bases of that plasticity are understood. In many clonal plants and colonial bryozoans, growth form is thought to be regulated by the relationships of metabolically active carbon and other metabolites between sources and sinks (Marshall 1990; Harvell and Helling 1993; Kemball and Marshall 1995; Miles et al. 1995). For example, since peripheral zooids along a growing margin of a bryozoan colony cannot feed (sinks), metabolites fueling their growth must be supplied from interior zooids (sources). In colonial hydroids, the volumetric rate of gastrovascular flow to the stolon tips similarly regulates morphological plasticity (Blackstone and Buss 1992, 1993). The present evidence, indicating a link between the physiology of internal transport and plasticity, suggests that clonal organisms are useful systems for studying mechanisms underlying phenotypic plasticity.

The encrusting colonial marine hydroid Hydractinia displays heritable variation in colony form with respect to the investments in stolonal mat, peripheral stolon (together, the vascular tissues), and polyp (ramet) tissues (McFadden et al. 1984; Blackstone and Yund 1989; Buss and Grosberg 1990; Blackstone and Buss 1991). Runner colonies exhibit substantial quantities of peripheral stolons relative to mat tissues, whereas sheet colonies produce an expansive, roughly circular stolonal mat that typically lacks peripheral stolons. Variation in Hydractinia colony form is representative of the morphological variation observed within and between various clonal taxa. Biologists studying plant, animal, and fungal systems have independently contrasted taxa that differ principally in the spatial arrangements of ramets and their vascular connections. Zoologists have labeled colonies with widely spaced ramets and long stolonal connections as "runners" and the converse as "sheets" (sensu Buss 1979; Jackson 1979), and botanists and mycologists have established a similar dichotomy between "guerilla" and "phalanx" morphologies (sensu Lovett-Doust 1981; Harper 1985).

The experimental evidence showing that colony form in hydroids is heritable and that perturbing vascular function changes the investment profile of polyps and stolons provides an opportunity to assess the lability and maintenance of colony form. In this contribution, we ask whether runners can be turned into sheets and vice versa. We show that the morphological trajectory of Hydractinia colonies is malleable to the extent that sheet (runner) phenotypes can be generated from runner (sheet) genotypes by decreasing (increasing) the variation in distribution of gastrovascular flow to the stolon tips of a colony. We suggest that the lability and maintenance of colony form is regulated through physiological conditions of circulation imposed by the relative sizes and arrangement (i.e., "architecture") of stolons in the mat. 

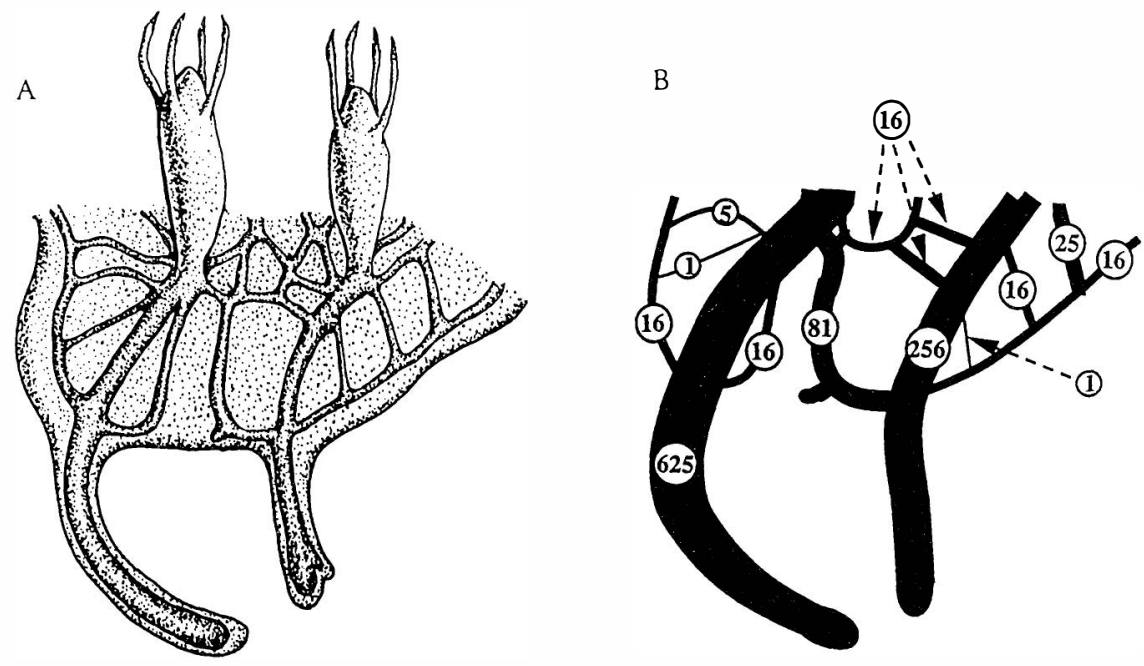

FIg. 1.-Diagram of a Hydractinia runner colony showing feeding polyps, stolonal mat, and peripheral stolons. Note in $A$ the presence of peripheral stolons, their relatively large diameter, the variable diameters of radial stolons, and an incomplete ring canal. $B$, Schematic diagram of relative volumetric distribution (indicated by relative line thicknesses) of gastrovascular flow among stolons depicted in $A$. Circled numbers are representative ratios of the diameter $^{4}$ of a given stolon to the diameter ${ }^{4}$ of the smallest stolon (i.e., those exhibiting relative unit diameter).

\section{BACKGROUND}

All three components of a colony (i.e., polyps, stolonal nat, and peripheral stolons) share a common gastrovascular system. The gastric cavity of polyps is continuous with the lumen of stolons. The stolonal mat, on which most polyps occur, is a closely knit complex of highly anastomosed stolons capped by a continuous layer of ectoderm. Two types of stolons populate the mat (fig. 1). Radial stolons extend outward from the colony center to its periphery like spokes on a wheel. Ring stolons, which arise from periodic lateral bifurcations of radial canals and subsequent anastomoses of lateral branches, are oriented circumferentially, encircling the colony perimeter (fig. 2). The mat grows at its periphery, extending as a sheet over the substratum. Peripheral stolons are radial canals that extend beyond the mat periphery (cf. fig. $1 A$ with fig. $2 A$ ).

Muscular contractions of polyps propel gastrovascular fluid through stolons to other polyps, thereby distributing metabolites (Berrill 1949; Hale 1960; Karlson and Marferin 1984; Marferin 1985; Schierwater et al. 1992; Buss and Vaisnys 1993). Flow can move in either direction within a stolon but cannot do so simultaneously. Fluids are circulated continuously, but circulation is a maximum $2-8 \mathrm{~h}$ following feeding (Schierwater et al. 1992). A velocity profile of digested particles moving fastest along the central axis and more slowly near the walls of stolons is apparent at $400 \times$ magnification ( $\mathrm{S}$. Dudgeon, personal observation). Flow 


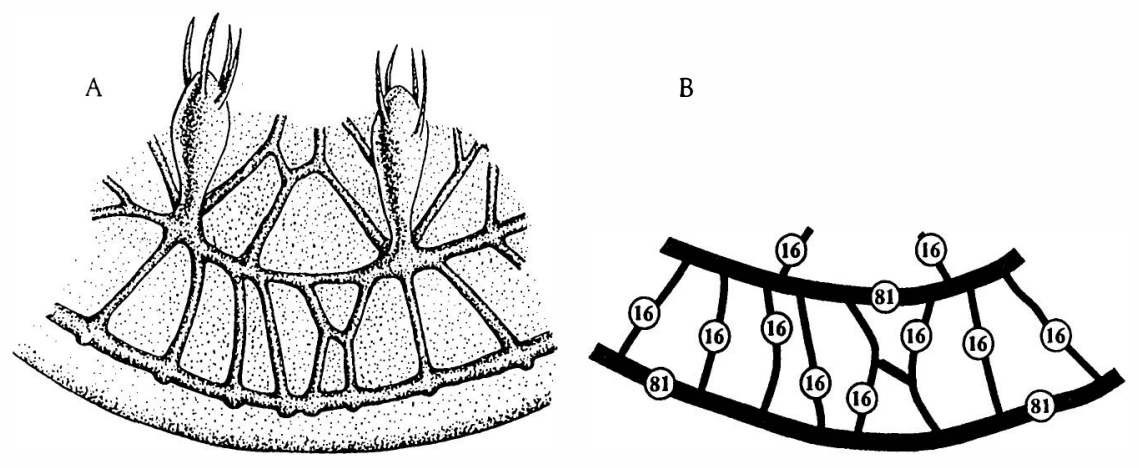

Fig. 2.-Diagram of a Hydractinia sheet colony showing feeding polyps and stolonal mat. Note in $A$ the absence of peripheral stolons, similar diameters among radial stolons, and a large, well-developed ring canal. $B$, Schematic diagram of relative volumetric distribution (indicated by relative line thicknesses) of gastrovascular flow among stolons depicted in $A$. Circled numbers are representative ratios of the diameter ${ }^{4}$ of a given stolon to the diameter ${ }^{4}$ of the smallest stolons (those with unit diameter) represented in fig. $1 B$.

through the gastrovascular system is laminar (Reynolds number $\approx 10^{-3}-10^{-2}$; S. Dudgeon, unpublished data).

The total flow through a stolon can be approximated by the Hagen-Poiseulle equation

$$
Q=\pi \Delta p a^{4} / 8 \mu l
$$

where $\Delta p$ is the pressure difference along a stolon of length $(l)$ imparted by polyp contraction, $a$ is the diameter of the stolon, and $\mu$ is the dynamic viscosity of hydroplasm (Vogel 1981). Because the volumetric rate of flow is proportional to the diameter of a stolon to the fourth power, small changes in the lumen diameter of a stolon greatly affect the volumetric rate passing through it. Moreover, wider stolons disproportionately increase their diameter compared to narrower stolons when pressurized (the law of LaPlace; see Vogel 1988), thereby supplying the former with the bulk of flow and nutrients.

Flow within a colony is thus a function of the relative diameters of stolons and of their patterns of connectivity to one another and to polyps. Runner and sheet colonies differ systematically in the dimensions of their respective stolon types (see Gastrovascular Architecture, below).

\section{GROWING-WITH-THE-FLOW MODEL}

We hypothesize that differences in stolonal arrangements and dimensions between runner and sheet colonies induce "self-maintaining" patterns of circulation. That is, the gastrovascular architecture of a runnerlike colony creates a flow pattern within the colony that ensures that, with growth, the same gastrovascular architecture will arise. Similarly, the sizes and arrangements of stolons within sheets create flow patterns that iterate a sheetlike gastrovascular architecture. 
Our reasoning is as follows. The periphery of a runner colony is characterized by great variation in the diameters of radial stolons and a small, often discontinuous ring canal (fig. 1A). Flow to peripheral stolon tips is maintained by a lower resistance to flow in larger, compared to narrower, stolons in the mat. Largerdiameter stolons receive disproportionately larger volumes of gastrovascular fluid (fig. $1 B$ ) and, hence, may elongate at disproportionately faster rates. In contrast, the periphery of sheet colonies is characterized by a continuous ring canal of relatively large diameter, in which radial canals terminate and from which radial stolon tips emerge (fig. 2A). Gastrovascular fluid entering the ring canal from radial stolons travels circumferentially around the periphery of the colony. Thus, any variation in flow among the similar-sized radial stolons can be equalized in the ring canal, and all stolon tips can be expected to receive equivalent volumes of gastrovascular fluid (fig. $2 B$ ). Since the rates of stolon elongation should be proportional to the volume of hydroplasm delivered to them, radial stolons will elongate at equivalent rates with the margin and extend over the surface as a sheet.

The spatial arrangement and relative sizes of stolons should act to deliver different hydromechanical signals and unequal rates of delivery of metabolites among stolons of runner colonies and similar hydromechanical signals and equivalent supply rates of metabolites among stolon tips of sheet colonies. Therefore, if the variation in stolon diameters of runner colonies could be reduced such that stolons received similar volumes of gastrovascular fluid, then the colony would adopt a sheetlike morphology. Conversely, if a disparity in stolon diameters at the margin of sheet colonies could be generated such that stolons received unequal volumes of gastrovascular fluid, then the colony would adopt a runnerlike morphology. If such transformations are possible, it implies that genotypic differences between morphological variants initially establish different size distributions of stolons, but, once established, the disparity is maintained by the local physiological states engendered (see Harvell 1991 for a discussion of selforganization in response to local physiological cues).

\section{GASTROVASCULAR ARCHITECTURE}

\section{Experimental Design}

The "grow with the flow" hypothesis minimally depends on the claim that systematic differences exist between runner- and sheetlike colonies in the dimensions of ring, radial, and peripheral stolons. To investigate this claim, we collected colonies of Hydractinia symbiolongicarpus from an intertidal site at Guilford, Connecticut, and maintained them in laboratory culture. Two genetic replicates of each of four runner and five sheet genotypes were used to compare stolon sizes of each morph. Polyps were surgically explanted onto $484-\mathrm{mm}^{2}$ glass cover slips and were held in place by a loop of thread until attachment, following which the threads were removed. Cover slips were placed in floating racks in $40-\mathrm{L}$ seawater (Reef Crystals, Aquarium Systems, Mentor, Ohio) aquaria at $22^{\circ} \mathrm{C}$ $\left( \pm 1^{\circ}\right)$ and fed to repletion with 3 - to 5 -d-old brine shrimp nauplii $3 \mathrm{~d}$ per week. 
Explanted colonies were grown for approximately $2 \mathrm{wk}$ to enable each replicate to attain the runner or sheet morphology characteristic of the clone prior to measuring stolon size distributions.

Measurements were made of the maximal diameters of radial, ring, and peripheral stolons of each colony. Such measurements require observing animals in the process of circulation since stolons are collapsible tubes and the lumen is effectively closed except when active gastrovascular exchange is occurring. To observe circulation in all experiments, we placed a colony in $0.22-\mu \mathrm{m}$ filtered seawater at $22^{\circ} \mathrm{C}\left( \pm 0.1^{\circ} \mathrm{C}\right)$ in a chamber mounted on the stage of an inverted microscope and viewed it through a $40 \times$ objective using differential interference contrast. Circulation was videotaped using a Dage MTI camera attached to the microscope and a VCR. Patterns of flow were videotaped $2-5 \mathrm{~h}$ following feeding at randomly selected $10^{5}-\mu \mathrm{m}^{2}$ quadrats around the margin of a colony. Flow through stolons in a quadrat was videotaped for 8-10 min (four to five polyp expansion/contraction cycles). For the analysis of lumen diameters of each morphology, one replicate stolon of each type was randomly selected within each of the five quadrats. In cases where a runner colony had $\leq 5$ peripheral stolons, all such stolons of the colony were videotaped. With the VCR connected to an image analysis system, images were acquired using a PCVISION frame grabber. The periodicity between cycles and maximum lumen diameter of stolons at the peak of an expansion cycle were determined using standard measurement algorithms available in the BioScan OPTIMAS (Version 3.10) image analysis software. The frequency of expansion cycles and the maximum diameter of the lumen are indicators of the volume flow through a stolon.

\section{Results}

Differences in the mean size and variance of the three stolon types exist between runner and sheet colonies (table 1). An ANOVA (table 2) indicates that the relative size of the lumen of radial and ring stolons varies with the morphology

TABLE 1

Relative Sizes and Variation in Size among Classes of Stolons in Both Runner- and SHEET-TYPe COLONIES OF HyDRACTINIA SYMBIOLONGICARPUS

\begin{tabular}{|c|c|c|c|c|c|c|}
\hline \multirow[b]{3}{*}{ Stolon Type } & \multicolumn{6}{|c|}{ COLONy MoRPHOLOGY } \\
\hline & \multicolumn{3}{|c|}{ SHEET TYPE* } & \multicolumn{3}{|c|}{ RUNNER TYPE } \\
\hline & Mean & Variance & $N$ & Mean & Variance & $N$ \\
\hline Ring & 19.37 & 26.17 & 50 & 15.14 & 23.55 & 40 \\
\hline Radial $(1+2$ combined $)$ & 14.77 & 16.61 & 50 & 22.78 & 146.37 & 72 \\
\hline Nonperipheral & 14.77 & 16.61 & 50 & 15.29 & 35.73 & 40 \\
\hline Peripheral & $\cdots$ & $\cdots$ & .. & 32.13 & 127.65 & 32 \\
\hline Total & 17.07 & 26.52 & 100 & 20.05 & 115.40 & 112 \\
\hline
\end{tabular}

NotE. - Lumen diameters of randomly selected stolons near the colony periphery were measured at the peak of an expansion cycle, in micrometers:

* None of the sheet colonies used in the analysis had peripheral stolons. 
TABLE 2

ANOVA Summary Table of the Results of Comparisons of Sizes of Ring and Nonperipheral Radial Stolons among Runner and Sheet Morphologies of HYDRACTINIA SYMBIOLONGICARPUS

\begin{tabular}{|c|c|c|c|c|c|}
\hline Source* & $\mathrm{df}$ & $\begin{array}{c}\text { Sum of } \\
\text { Squares }\end{array}$ & $\begin{array}{c}\text { Mean } \\
\text { Square }\end{array}$ & $F$ & $P$ \\
\hline Stolon type & 1 & .196 & .196 & 18.26 & $<.01$ \\
\hline Morphology & 1 & .128 & .128 & 1.72 & $>.10$ \\
\hline Stolon $\times$ morphology & 1 & .159 & .159 & 14.75 & $<.01$ \\
\hline Genotype(morphology) $\dagger$ & 7 & .446 & .064 & .77 & $>.50$ \\
\hline Colony (genotype(morphology)) & 9 & .744 & .082 & 7.67 & $<.01$ \\
\hline Stolon $\times$ genotype (morphology $) \dagger$ & 7 & .093 & .013 & 1.25 & $>.25$ \\
\hline Stolon $\times$ colony $($ geno- & & & & & \\
\hline type $($ morphology $)) \dagger$ & 9 & .056 & .006 & .57 & $>.82$ \\
\hline Error & 144 & 1.574 & .011 & 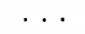 & $\cdots$ \\
\hline
\end{tabular}

NotE.-Peripheral stolons of runner colonies were excluded from the analysis for two reasons: inclusion of peripherals as radials results in heteroscedasticity of the variances even following a logarithmic transformation, and since replicates of the sheet morph had no peripheral stolons, their inclusion provided no meaningful comparisons. Data were log transformed prior to analysis to meet the assumptions of homogeneity of variances $\left(F_{\max }\right.$ test) and normality.

* Stolon type and morphology are considered fixed, orthogonal factors; genotype is a random factor nested within morphology; and colony is a random factor nested within genotype.

$\dagger$ Source of variation was pooled post hoc with an appropriate error term as discussed by Underwood (1981) because of a sufficiently small mean square.

of the colony (i.e., stolon $\times$ morphology interaction). Thus, radial canals of sheet colonies are smaller (and more uniform in size) than those of runner colonies. In contrast, ring canals are larger in sheet than in runner colonies. Moreover, in spite of significant differences in stolon size among replicate colonies within genotypes of both sheet and runner forms (colony nested within genotype and morphology mean square), the relative sizes of radial and ring stolons did not vary among colonies, or among genotypes, within each of these forms (stolon $\times$ colony(genotype(morphology)) and stolon $\times$ genotype(morphology) mean squares). Peripheral stolons, restricted to runner forms, exhibit the greatest lumen diameters of all the stolon classes and greater variation in lumen size than radials restricted to the mat. Additional data for a second species, Hydractinia echinata, indicate that the relative sizes of radial and ring stolons vary with colony morphology similarly across both taxa $\left(F_{\text {stol } \times \text { morph }}=8.61\right.$, df $=1,206, P<.01$, $F_{\text {species } \times \text { stol } \times \text { morph }}=0.01, \mathrm{df}=1,3, P>.90$; data not shown).

\section{CAN RUNNERS BE TRANSFORMED INTO SHEETS?}

We sought to eliminate the disparity of stolon diameters within a colony that characterize runner clones by redistributing gastrovascular flow through surgical manipulation, thereby transforming runners into sheets. Our rationale was to remove all peripheral stolons, causing the flow within radial canals that once led to each peripheral stolon to be redistributed into other canals in the mat. If the colony is thereafter prevented from growing new peripheral stolons, the radial 
canals within the mat will grow to accommodate the increased volumes being delivered to them, thereby reducing the variation in radial stolon diameters and establishing the physiological conditions that we hypothesize maintain the sheet morphology.

\section{Experimental Design}

Twenty explants of three to five polyps each were grown from a single runnertype clone in a floating rack at $22^{\circ} \mathrm{C}$ and were randomly assigned to either of two treatments of 10 replicates each, controls or treated colonies in which stolonal connections were manipulated. Explanted colonies were grown for approximately 2 wk to enable each replicate to attain the runner morphology characteristic of the clone.

Following initial measures of circulation and morphometry (described below), treatment of experimental colonies was initiated. The redistribution of gastrovascular flow was effected indirectly by surgically removing all peripheral stolons at the edge of the stolonal mat from each colony with a microscalpel, which caused hydroplasm to flow elsewhere. Cut stolons heal within seconds, and such treatment does not adversely affect the overall growth rate of a colony (Buss and Blackstone 1991). All colonies were examined under a dissecting microscope at $32 \times$ two to three times per day, and peripheral stolons were removed from each treated colony as they were detected emerging from the stolonal mat (typically, once or twice daily). This treatment was continued daily for $17 \mathrm{~d}$, whereupon experimental colonies rarely (if at all) initiated new peripheral stolon tips. At this point, gastrovascular flow of each colony was videotaped to document whether the treatment had altered the architecture of the stolonal mat and patterns of flow. Two representative stolons from each of five randomly selected quadrats per colony were chosen for analysis of changes in gastrovascular architecture as described above. From the samples of stolon sizes, the values of within-colony variance, skewness, or kurtosis $(N=10$ colonies/treatment) that reflect the stolonal architecture and, hence, distribution of flow within a colony were calculated for each colony. The values were compared between treatments using a onefactor ANOVA to assess whether removing peripheral stolons significantly altered stolonal architecture. The effect of the manipulation on gastrovascular flow was assessed in those subsamples of control and experimental replicates for which maximum flow speeds in a quadrat could be estimated before and after severing stolons. The largest-diameter stolon (having the greatest flow speed) was used for analysis in each quadrat. The distance traveled by a tracked particle divided by the temporal resolution of successive video frames $(0.4 \mathrm{~s})$ was used to estimate the speed of a particle in flow. Sampling was confined as much as possible to the smallest detectable particles traveling at, or near, the midline of the stolon lumen to minimize errors of estimating flow speeds due to heterogeneous particle sizes and the effect of the lumen wall. After filming, all peripheral stolons were removed from both control and treated replicates, and the colonies were allowed to grow without further manipulation. After $10 \mathrm{~d}$, the growth trajectory of each colony was determined. The effect of flow patterns on colony morphology was assessed by comparisons of morphological parameters of control and treated colonies. 
Image analysis was used to quantify morphological parameters of each replicate colony before and after experimental manipulation. A Cohu CCD camera with a macrolens was used to project a colony image onto a video monitor connected to a PC-compatible computer. Background-subtracted images of each colony were acquired and stored as computer image files. Image files of colonies consisted of three distinct luminance levels representing polyps (brightest luminance), stolons (intermediate luminance), and background (darkest).

Image files were used to calculate the following morphological characteristics for each colony; perimeter $/ \sqrt{\text { area }}$, number of stolon tips/unit colony perimeter, polyp area/stolon area, and $r$, the length of the mean vector indicating whether colony growth (as indexed by polyp placement) was directional. Perimeter $/ \sqrt{\text { area }}$ (see Blackstone and Buss 1991 for a discussion of this metric) and number of tips/colony perimeter are indexes that characterize the gross morphology of colonies along the continuum from sheet to runner; greater values of each index indicate a more runner-type morphology. Polyp area/stolon area characterizes the relative rates of production of polyps versus stolon tissue. Values for these parameters were compared among treatments using ANOVA (SAS version 6.0). Data were log transformed prior to analysis in order to meet the assumptions of homogeneity of variances and normality.

The vector length, $r$, is based on the mean angle of growth determined from the polar coordinates (relative to the center of the explant) of polyps of a colony (Batschelet 1981). Values of $r$ vary between zero and one; $r=0$ indicates a uniform distribution of polyps about the colony center, whereas $r=1$ indicates that all polyps are distributed in the same direction. We considered only the question of whether colonies exhibited directional growth and were not concerned with the specific direction of growth by each colony. The probabilities of vector lengths between zero and one representing directional growth are known and depend on sample size (Batschelet 1981). Given this fact and that the number of polyps varies among colonies, values of $r$ were determined from a randomly selected subset of the polyps of each colony. The number of polyps selected for analysis was determined by the maximum number of polyps per colony that could be selected that included all replicates of each treatment $(N=10$ in runner-tosheet experiment). However, one replicate in the runner-to-sheet experiment was excluded from the analysis because it had less than 10 polyps at the end of the experiment. Comparisons between the randomly selected subsets and wholecolony data for each colony indicated that the randomly selected subsets were representative of the direction of growth for each colony (mean difference in direction $\pm \mathrm{SE}$ of $N=10$ [runner-to-sheet experiment], $13.8^{\circ} \pm 2.6^{\circ}$ ). The distributions of $r$ values for each treatment were compared to a theoretical distribution of $r$ values of equal sample size representing uniform (nondirectional) growth using the Kolmogorov goodness-of-fit test (Conover 1981).

\section{Results}

Measures prior to experimental manipulation indicate that control and treated colonies both exhibited a runner morphology and were similar with respect to patterns of gastrovascular flow (perimeter $/ \sqrt{\text { area }}=17.52 \pm 2.76,19.22 \pm 2.97$; tips $/ \mathrm{cm}$ perimeter $=5.15 \pm 1.01,4.86 \pm 1.08$, for control and treated colonies, 


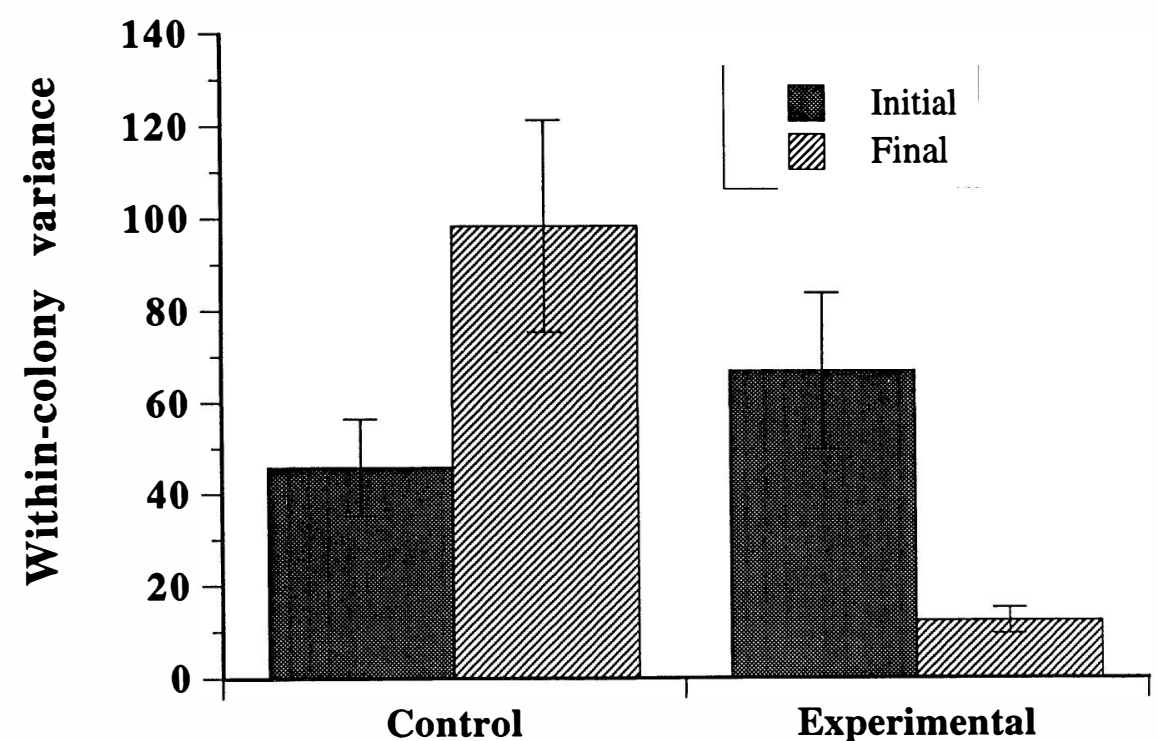

Treatment

Fig. 3.-Variance of stolon diameters within replicate colonies for control and experimental treatments before (stippled bars) and after (hatched bars) experimental manipulation. Values represent means \pm SEs of $N=10$ sample variances in each treatment.

respectively). The size-frequency distribution of maximum lumen diameters of stolons showed a similar pattern among treatments with respect to mean size, variance, skewness, and kurtosis within a colony, as well as periodicity of circulation-hence, the distribution of flow throughout a colony (mean, $F=0.87$, $\mathrm{df}=$ $1,18, P>.25$; variance, $F=0.58$, df $=1,18, P>.45$, skewness, $F=0.79$, df $=1,18, P>.38$; kurtosis, $F=0.44$, df $=1,18, P>.51$; periodicity, $F=$ 1.28 , df $=13,42, P>.26)$.

Removal of peripheral stolons altered the size-frequency distributions of stolons in the mats of experimental colonies. The variation among maximum lumen diameters of stolons within a colony was significantly reduced in treated colonies relative to controls $(F=31.52$, df $=1,18, P<.01$; fig. 3$)$. In addition, the size-frequency distribution of stolons of treated colonies became leptokurtotic and less skewed relative to that of control colonies (skewness, $F=10.52$, df $=$ $1,18, P<.01$; kurtosis, $t$-test for unequal variances, $t=2.60, \mathrm{df}=10.5, P=$ $.03)$. Removal of peripheral stolons had no effect on the periodicity of expansion/ contraction cycles (i.e., pumping behavior; $F=0.30$, df $=1,18, P>. .50$ ). We interpret these changes in variance, skewness, and kurtosis of the population of stolons within a colony to reflect greater uniformity in the distribution of gastrovascular flow throughout (fig. 4). In support of our interpretation is evidence that manipulating stolonal connections altered characteristics of gastrovascular flow, as represented here by the speed of flow. Maximum flow speeds through stolons 


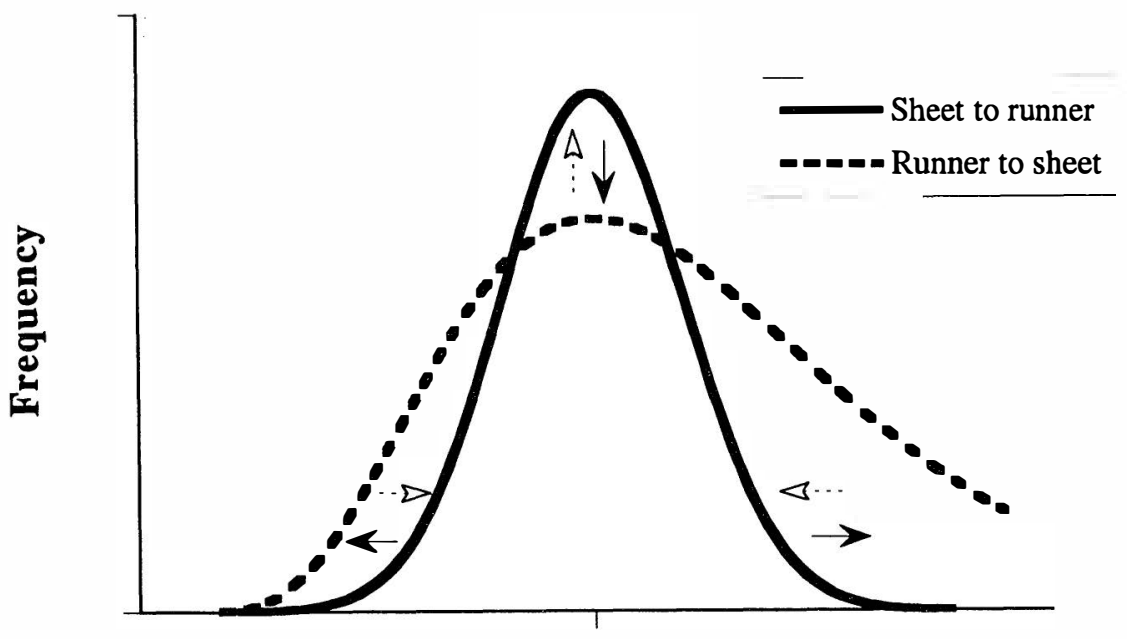

\section{Stolon size class}

FIG. 4.-Schematic diagram showing transition between size-frequency distributions of stolons in the mat associated with morphological transformation between runner and sheet morphologies, and vice versa, in a Hydractinia symbiolongicarpus colony.

of control colonies during the course of the experiment either overlapped with or were greater than those observed at the outset (fig. $5 A$ ). In contrast, the distribution of maximum flow speeds through stolons in the quadrat tended to decrease in each replicate sampled after experimental manipulation (fig. $5 B$ ). The patterns of flow speed observed in the two treatments during the course of the experiment are qualitatively similar to those observed in the variation of stolon diameters (cf. fig. 3 with fig. 5).

Coincident with changes in patterns of gastrovascular flow was a significantly lower rate of production of peripheral stolons and a more sheet-type morphology exhibited by treated colonies (table 3 ). The sample of mean vectors, $r$ (based on a first-order sample of $N=10$ polyps/colony), showed that control colonies exhibited directional growth even after regrowth following peripheral stolon removal $\left(D_{\max }=0.88, N=10, P<.01\right.$; fig. $\left.6 A, B\right)$. In contrast, altered patterns of gastrovascular flow in treated colonies resulted in a uniform distribution $\left(D_{\max }=0.34, N=9, P>.10\right)$ of the placement of polyps about the center of the explant (fig. $6 C, D$ ). Although altering flow affected the placement of polyps within a colony, it did not affect the relative rate of production of polyp versus stolon tissue (table 3 ).

\section{CAN SHEETS BE TRANSFORMED INTO RUNNERS?}

Transformation of sheets to runners was attempted by creating a disparity in stolon sizes by redistributing gastrovascular flow through surgical manipulation of 


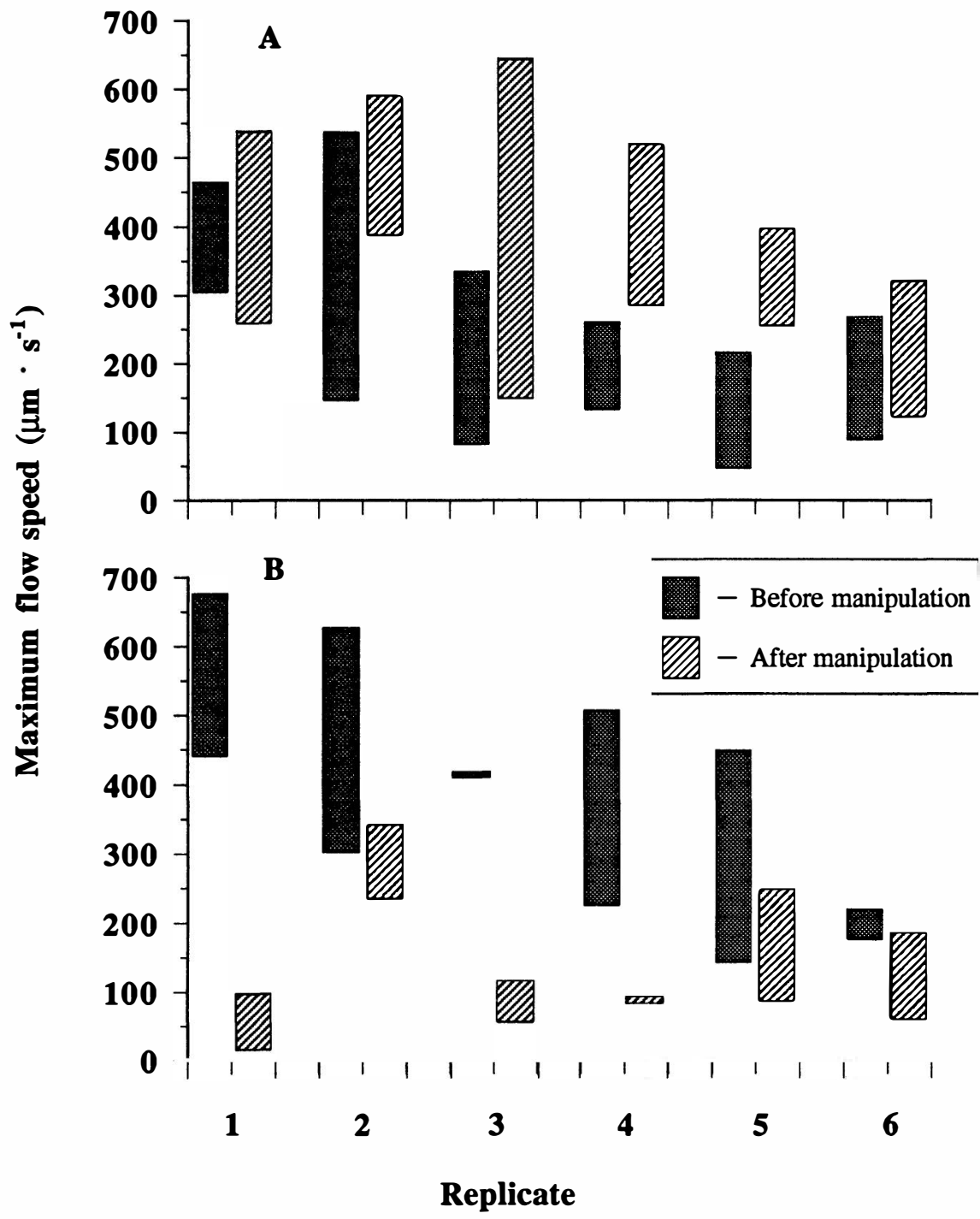

FIG. 5.- Maximum flow speed in a quadrat sampled before (stippled bars) and after (hatched bars) severing stolonal connections in $(A)$ six control replicate colonies and $(B)$ six experimental replicate colonies. Bars represent the range of maximum speeds of tracked particles in a stolon. Variation in flow speeds among replicate colonies reflects variation in the diameter of the stolons sampled. Number of particles tracked per stolon ranged from two to 23 , except experimental replicate 3 before manipulation, where only one particle was tracked. 
TABLE 3

Morphological Characterization of Control and Experimental Colonies Following io d of Regrowth after Removing All Peripheral Stolons from All Colonies in Each Treatment

\begin{tabular}{|c|c|c|c|c|c|c|c|c|}
\hline \multirow[b]{3}{*}{ Parameter } & \multicolumn{5}{|c|}{ Treatment } & & \multirow[b]{3}{*}{$F$} & \multirow[b]{3}{*}{$P$} \\
\hline & \multicolumn{3}{|c|}{ CONTROL } & \multicolumn{2}{|c|}{ EXPERIMENTAL } & & & \\
\hline & $N$ & Mean & $\mathrm{SE}$ & $N$ & Mean & $\mathrm{SE}$ & & \\
\hline Perimeter $/ \sqrt{ }$ area & 10 & 9.95 & 1.48 & 10 & 5.09 & .38 & 15.18 & $<.01$ \\
\hline Tips $/ \mathrm{cm}$ perimeter & 10 & 4.27 & .55 & 10 & 1.81 & .70 & 7.66 & .01 \\
\hline$r$ (mean vector length) & 10 & .67 & .04 & $9^{*}$ & .43 & .07 & $\cdots$ & $\cdots$ \\
\hline Polyp area/mat area & 10 & .09 & .01 & 10 & .09 & .02 & .02 & .90 \\
\hline
\end{tabular}

Note.-Values represent means and SEs.

* One replicate colony did not have the 10 polyps required for an analysis of directionality.

the peripheral ring canal. Severing the ring canal should disrupt the equalization in volume of gastrovascular flow to the emerging stolon tips, which would generate local asymmetries in flow. Any such asymmetry will result in an increased diameter of radial stolons, which facilitates delivery of greater fluid volumes. Subsequently, peripheral stolons are expected to develop and be maintained because they carry disproportionately larger volumes of fluid. This would be expected to create the physiological conditions hypothesized to maintain runner-type morphologies.

\section{Experimental Design}

Twenty-four explants of two polyps each were grown from a single sheet-type clone in floating racks at $22^{\circ} \mathrm{C}$ and were randomly assigned to one of three treatments of eight replicates each: unmanipulated controls, severing of the peripheral ring canal, and piercing the epithelium of the stolonal mat without severing any stolons. Since a nerve net occurs in the stolonal mat of Hydractinia (Müller 1964), the third treatment was included to distinguish between morphological effects associated with mechanical disruption to the mat and those associated with the redistribution of flow.

Explanted colonies were grown for approximately $2 \mathrm{wk}$ to enable each replicate to attain the sheet morphology characteristic of the clone. The ring canal of experimental colonies, viewed under a dissecting microscope at $32 \times$, was severed at several points along the perimeter with a microscalpel every $2 \mathrm{~h}$ for $16 \mathrm{~h}$ a day, daily for $20 \mathrm{~d}$. Severing of the ring canal was normalized to colony size by making one cut for every $4 \mathrm{~mm}$ of colony perimeter. The locations of cuts were randomly determined prior to initiating the experiment, and subsequent cuts were made in the same location. Similarly, the epithelia of sham-manipulated colonies were pierced with the tip of a microscalpel at randomly selected points around the colony perimeter at a density of one cut/4-mm perimeter every $2 \mathrm{~h}$ for $16 \mathrm{~h}$ per day, daily for $20 \mathrm{~d}$. Following $20 \mathrm{~d}$ of experimental manipulation and the final videotaping of patterns of gastrovascular flow, any peripheral stolons that had developed in colonies of any treatment were removed, and the colonies 
A. Control colonies; initial mean vectors

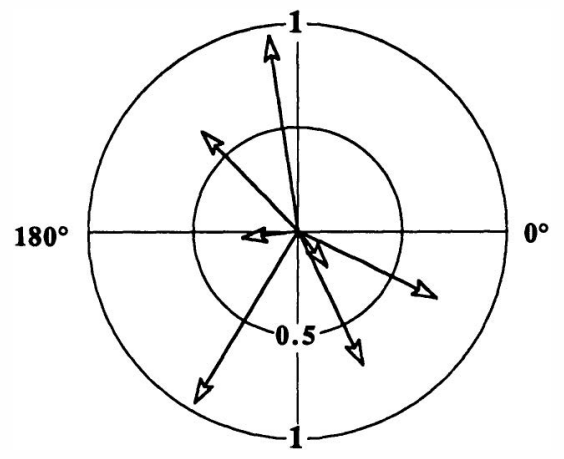

C. Treated colonies; initial mean vectors

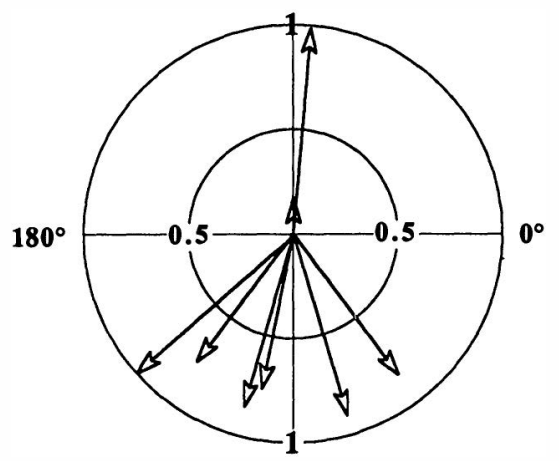

B. Control colonies; final mean vectors

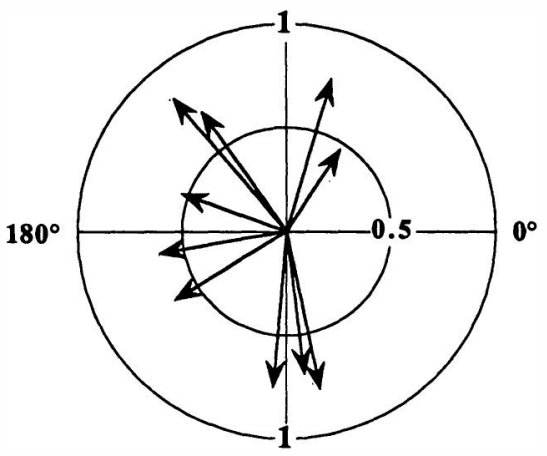

D. Treated colonies; final mean vectors

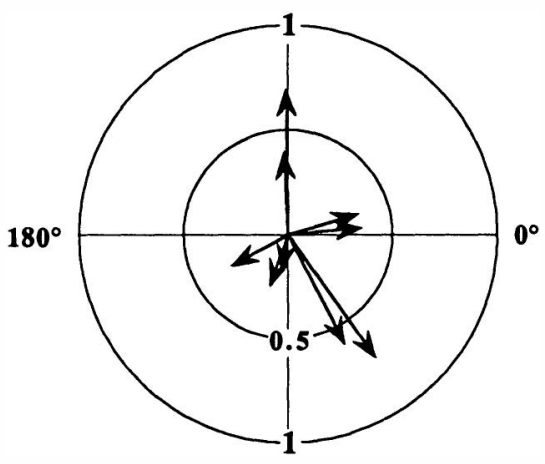

Fig. 6. - Mean vectors of each replicate describing directionality of growth of polyps prior to (open arrowheads) and following (solid arrowheads) manipulation for control ( $A$ and $B$ ) and experimental $(C$ and $D$ ) colonies. The direction of each vector indicates mean angle of growth of a replicate colony, and length of the vector is a measure of variation from that direction (longer vectors represent low-variation, highly directional growth). The concentric circles of radii equal to 0.5 and 1 , respectively, are scales to compare vector lengths distributed around the coordinate axes.

were allowed to continue growing without further manipulation. Backgroundsubtracted images of colonies for morphometric analysis were acquired prior to manipulation, after 10 and $20 \mathrm{~d}$ of surgical manipulation, as well as following 10 $\mathrm{d}$ of regrowth after manipulations were terminated. Twenty-five polyps/colony were used as a first-order sample in the analysis of directionality in the sheet-torunner experiment. These random subsets were representative of the direction of growth for colonies in this experiment (mean difference in direction \pm SE of $N=25 ; 26.9^{\circ} \pm 11.7^{\circ}$. 
The objective of this experiment was to determine whether experimentally generating a disparity in the diameters of stolons resulted in a runner morphology. Only three of eight experimental replicates met the condition (a disparity in stolon sizes) that we sought to test, and only those three colonies were included in subsequent analyses of morphological data. The remaining five replicates in which flow patterns were not successfully altered maintained a sheet growth trajectory (i.e., they were effectively additional control replicates). The criterion for significant change in stolon sizes was determined a posteriori from the analysis of within-colony variation in stolon diameters before and after experimental manipulation compared to unmanipulated (control) colonies and colonies with pierced epithelia. Specifically, the within-colony variance, which reflects distribution of flow within a colony, was calculated from the sample of stolons $(N=16$ : two representative stolons from each of eight randomly selected quadrats) for each colony. The mean and standard deviation of the combined sample of withincolony variance values for unmanipulated colonies and colonies with pierced epithelia ( $N=16$; eight control and eight pierced-epithelium colonies) were determined. Experimental colonies having a within-colony variance of $\geq 3$ SDs beyond the mean of the combined sample following experimental manipulation were considered to have altered stolonal architectures.

The failure of severing the ring canal to uniformly elicit sufficient within-colony variability in flow patterns has at least three potential causes. The density of cuts used in our experiment may not consistently generate variability in the distribution of flow among radial canals at the colony margin. Furthermore, in welldeveloped sheets, variation in flow may be partially equalized interior to the colony margin by inner networks of ring canals. Finally, because severed ring canals generally fuse within $3 \mathrm{~h}$ and gastrovascular flow was disrupted for only $\approx 16$ of every $24 \mathrm{~h}$, uninterrupted flow through the ring canal was possible for a few hours each day, which may have equalized any locally generated variability in the distribution of flow.

\section{Results}

Colonies from all treatments exhibited sheet morphologies with no peripheral stolons present prior to manipulation (perimeter $/ \sqrt{\text { area }}=3.69 \pm 0.02,3.71 \pm$ $0.04,3.69 \pm 0.02$ for controls, treated, and sham-manipulated colonies, respectively). The periodicity of expansion/contraction cycles and sizes of the lumen of stolons were also similar among colonies in each treatment $(\approx 110 \mathrm{~s} / \mathrm{cycle}$ and $\approx 14 \mu \mathrm{m}$ in diameter, respectively), with little within-colony variation (withincolony variance $=9.31 \pm 1.57,10.24 \pm 2.24,12.14 \pm 4.20$, for controls, treated, and sham-manipulated colonies, respectively; fig. 7). Therefore, the distribution of gastrovascular flow varied little both within colonies and among colonies in each treatment prior to severing the ring canal.

The variation in stolon diameters within colonies before and after experimental manipulation is shown in figure 7. In contrast to the three experimental replicates, both control and sham-manipulated colonies showed little increase in stolon size variation during the experiment. The greater variation in experimental colonies was associated with the development of peripheral stolons and a smaller propor- 


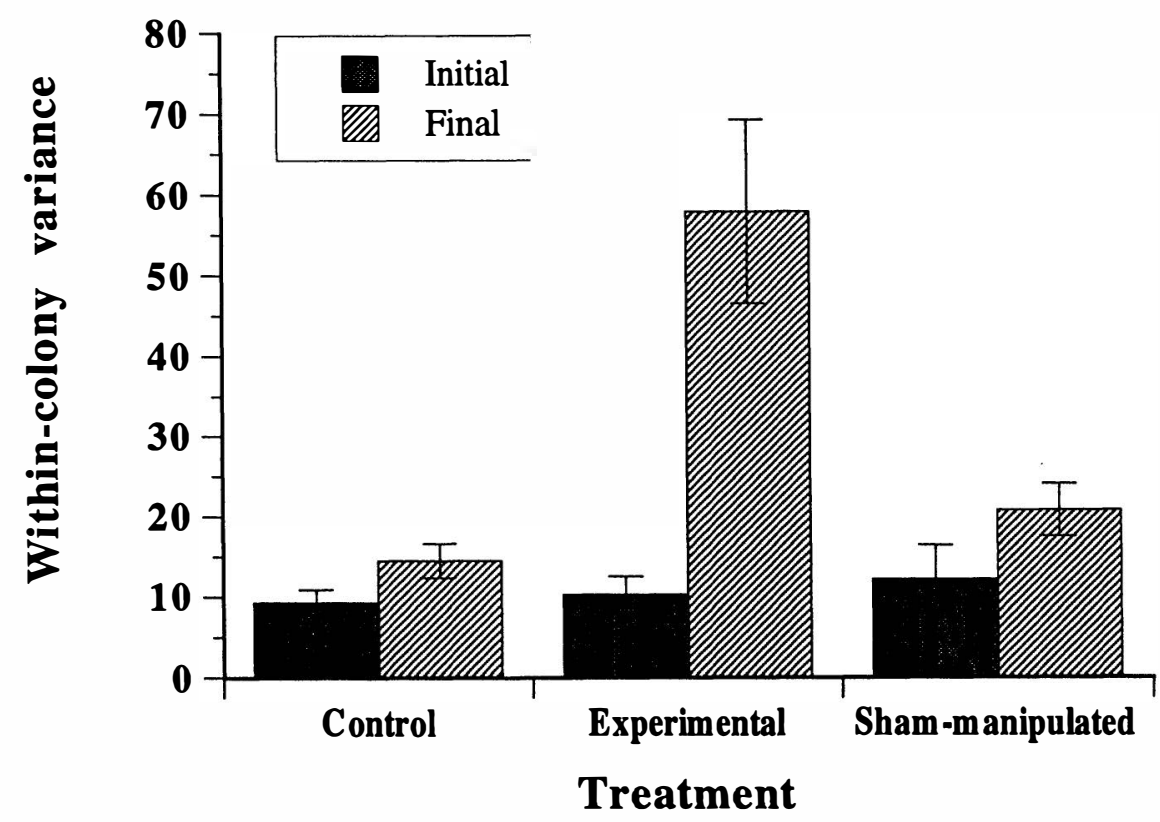

FIG. 7.-Variance of stolon diameters within replicate colonies for control, experimental, and sham-manipulated treatments before (stippled bars) and after (hatched bars) experimental manipulation. Values represent means \pm SEs of $N=8$ sample variances in each treatment, except the final measures of experimental colonies, where $N=3$.

tion of stolons in the modal size class ( $\approx 14$ - to 20 - $\mu$ m diameter; data not shown). The greater variation in stolon diameters within experimental colonies indicates greater variation in the distribution of gastrovascular fluid to different regions of the colony (fig. 4).

Increased variation in stolon diameters within colonies resulted in a proliferation of peripheral stolons and, consequently, an increase in perimeter $/ \sqrt{\text { area }}$ (fig. 8). The first $10 \mathrm{~d}$ were characterized by a proliferation of several peripheral stolons and initiation of a runner growth trajectory. From day 10 to day 20 the number of tips emerging from the mat declined (i.e., tissue resorbed); however, the perimeter $/ \sqrt{\text { area }}$ index continued to increase as the network of remaining peripheral stolons became larger and more complex. In contrast, few stolon tips emerged from the stolonal mats of colonies of the two control treatments, and, consequently, little change in perimeter $/ \sqrt{\text { area }}$ values was observed during this period. Therefore, we interpret observed morphological effects as resulting from the redistribution of gastrovascular flow associated with the severing of the ring canal and not merely from mechanical disruptions of the stolonal mat. Peripheral stolons again developed in the three experimental colonies within the $10 \mathrm{~d}$ following their removal on day 20 , which indicates that these colonies were exhibiting a runner growth trajectory (table 4). In contrast, no peripheral stolons developed on any replicate in either the unmanipulated or pierced-epithelium colonies, and these colonies continued growth as circular encrusting sheets. 


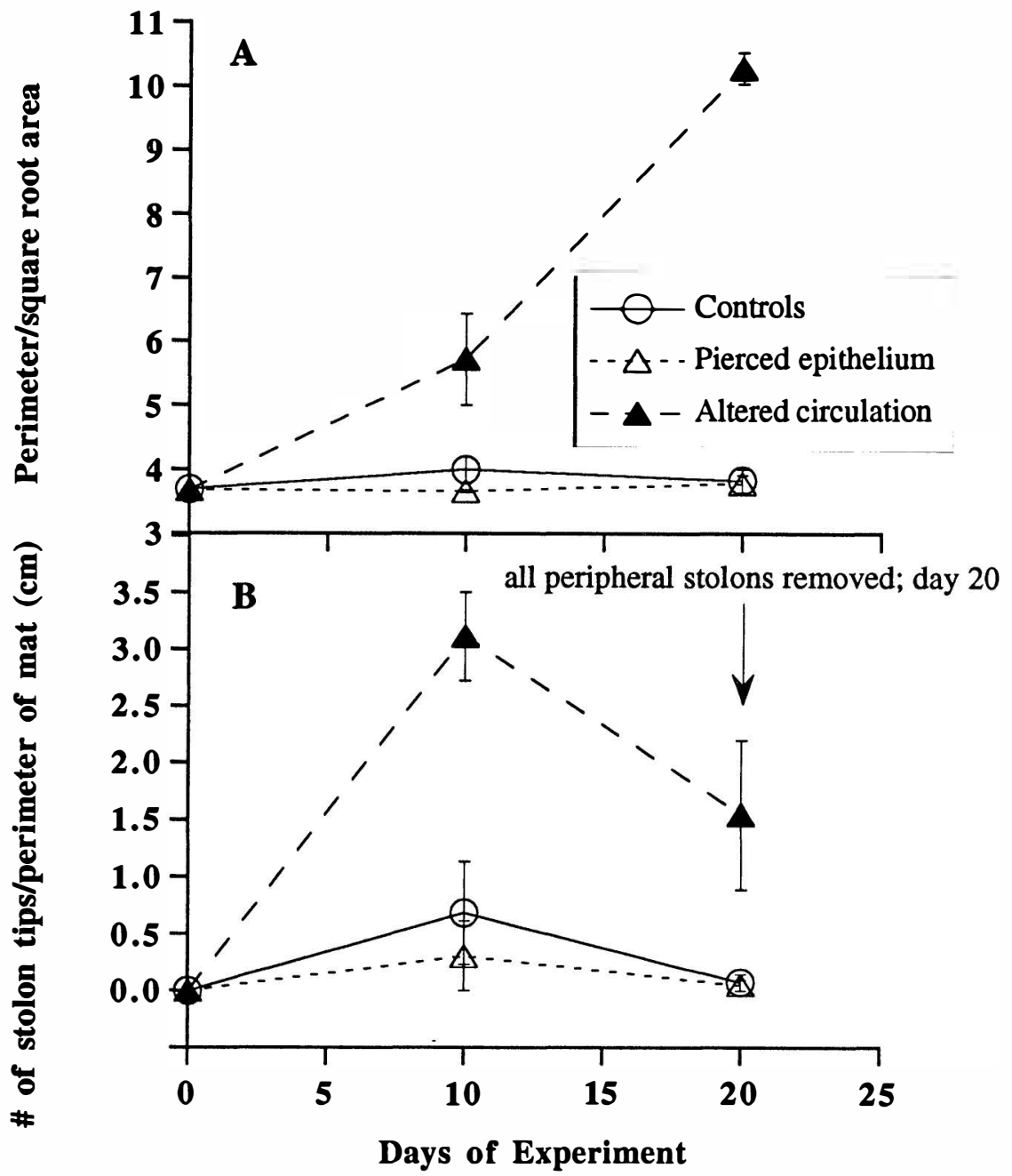

FIG. 8.- Time course of morphological changes as indexed by $(A)$ the ratio of colony perimeter to the square root of area and $(B)$ the number of stolon tips per centimeter of colony perimeter projecting from the stolonal mat of control (open circles), experimental (solid triangles), and sham-manipulated (open triangles) colonies during the sheet-to-runner experiment. Symbols represent means \pm SEs of $N=8$, except for experimental colonies, where $N=3$. All peripheral stolons were removed on day 20 , and colonies were allowed to grow without further manipulation.

No directionality in the placement of polyps of colonies was observed in any treatment prior to the experiment (data not shown). At the end of the experiment, directional growth of polyps was observed only among the unmanipulated control colonies $\left(D_{\max }=0.69, N=8, P<.01\right.$; fig. 9). Colonies in which either the ring canal was severed or the epithelial tissue was pierced showed growth of polyps that was not distinguishable from a uniform pattern of growth (severed ring colo- 
TABLE 4

Morphological Characterization of Colonies with Altered Circulation, with Pierced Epithelia Only, or Unmanipulated Following io d of Regrowth after Removing All Peripheral Stolons from All Colonies in Each Treatment

\begin{tabular}{|c|c|c|c|c|c|c|c|c|c|c|c|}
\hline \multirow[b]{3}{*}{ Parameter } & \multicolumn{9}{|c|}{ TREATMENT } & \multirow[b]{3}{*}{$F$} & \multirow[b]{3}{*}{$P$} \\
\hline & \multicolumn{3}{|c|}{$\begin{array}{l}\text { UNMANIPULATED } \\
\text { CONTROL }\end{array}$} & \multicolumn{3}{|c|}{$\begin{array}{c}\text { ALTERED } \\
\text { CIRCULATION }\end{array}$} & \multicolumn{3}{|c|}{ PIERCED EPITHELIA } & & \\
\hline & $N$ & Mean & SE & $N$ & Mean & SE & $N$ & Mean & SE & & \\
\hline Perimeter/ $\sqrt{ }$ area & 8 & 3.72 & .04 & 3 & 4.34 & .33 & 8 & 3.74 & .02 & 9.55 & $<.01$ \\
\hline Tips/cm perimeter & 8 & .00 & .00 & 3 & 2.35 & 1.77 & 8 & .00 & .00 & $\cdots$ & $\cdots$ \\
\hline$r($ mean vector length) & 8 & .36 & .05 & 3 & .22 & .12 & 8 & .27 & .05 & $\cdots$ & $\cdots$ \\
\hline Polyp area/mat area & 8 & .06 & .004 & 3 & .06 & .003 & 8 & .07 & .001 & .45 & .88 \\
\hline
\end{tabular}

Note._Values represent means and SEs.

nies, $D_{\max }=0.37, N=3, P>.2$; pierced-epithelium colonies, $D_{\max }=0.20, N$ $=8, P>.2$ ). No difference in the relative production of polyps versus stolon tissue was observed among the three treatments (table 4).

\section{DISCUSSION}

Our results show that different colony forms, runner and sheet, exhibit different gastrovascular architectures and that altering patterns of gastrovascular flow changes the morphological trajectory of developing colonies to the extent that runners can be transformed into sheets and vice versa. Thus, despite a heritable basis, colony form in Hydractinia is quite malleable. The malleability of colony form is controlled by the extent to which the stolonal architecture, and the flow patterns it imposes, can be altered.

Our conclusions regarding the extent of plasticity and the physiological processes that mediate it assume that the single runner and sheet genotypes used in our experiments are representative of each morphological type. Two lines of evidence support our assumption. First, all colonies regardless of genotype operate under the same principles of fluid mechanics. Therefore, the particular choice of genotype, in principle, should not matter. If a stolon is severed, gastrovascular flow in that stolon must be redistributed elsewhere in the colony. Hence, our surgical manipulations may redistribute flow and affect morphological patterning similarly across genotypes. Second, we observed no variation in the relative sizes of stolon types either within or among genotypes of either morphology. Nevertheless, it is possible that genetic variation for the repatterning of the stolonal architecture exists, as well as variation for morphogenetic responses to the altered flow patterns. Experiments with additional genotypes of each morph are necessary to determine whether genetic variation for morphological plasticity exists.

The importance of distribution of flow to the regulation of growth form, as exemplified by Hydractinia, may be of general significance among clonal organ- 


\section{A. Control colonies; final mean vectors}

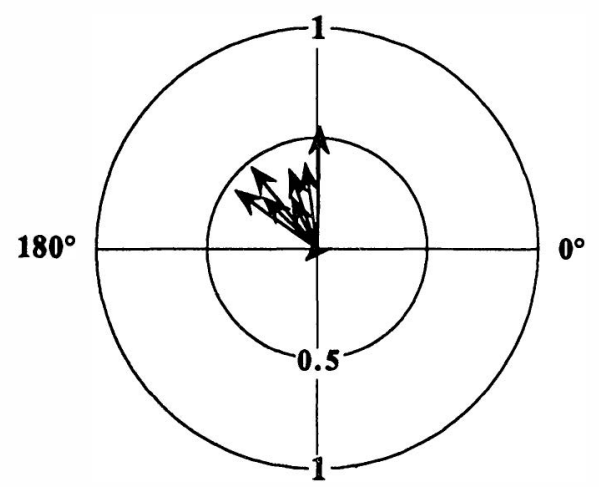

B. Severed ring canal; final mean vectors

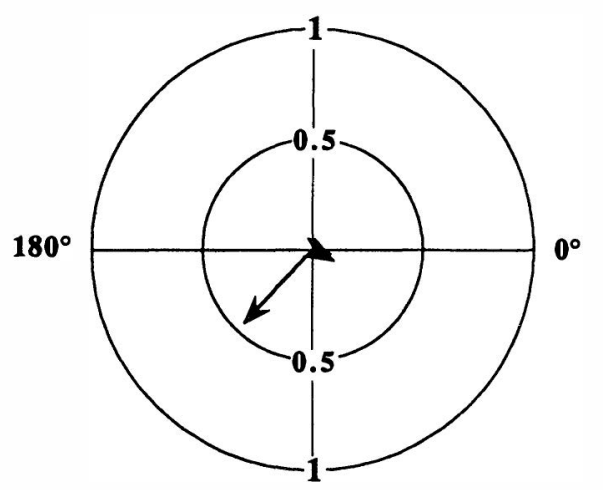

C. Pierced epithelial tissues; final mean vectors

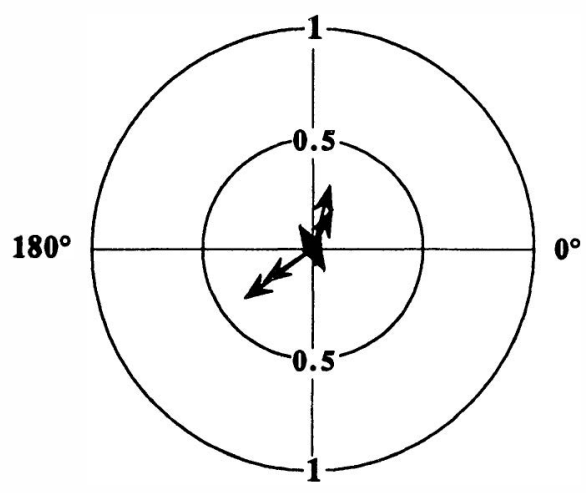

FIG. 9.- Mean vectors of each replicate describing directionality of growth of polyps following manipulation of circulation of control $(A)$, experimental $(B)$, and sham-manipulated (C) colonies. Representation of vectors is as described in fig. 6. 
isms. In the bryozoan, Membranipora membranacea, growth of colonies is regulated by the translocation of metabolites among zooids through the funicular system from source to sink (Harvell and Helling 1993; Miles et al. 1995). Moreover, it is likely that translocation through axial pore plates of zooids is greater than that through lateral pore plates (D. Harvell, personal communication). If so, this may facilitate a disparity in the distribution of metabolites by localizing it among particular zooids (sinks) in a colony. Disrupting the growing margin of a Membranipora colony induces polymorphism and alters growth patterns through shifts in the distribution of flow and allocation of metabolites among zooids. In the clonal plant white clover (Trifolium repens), variation in the distribution of assimilated carbon among main stolons and branch stolons, both near and far from the metabolite source, regulates patterns of growth (Kemball and Marshall 1995).

\section{Hydromechanical Control of Colony Form}

Our results, as well as prior work with hydractiniid gastrovascular systems, are readily interpretable in terms of the Hagen-Poiseulle equation. Whereas the present study demonstrates that colony form can be altered by locally manipulating the stolonal architecture to change flow patterns (i.e., manipulation of $a$ in eq. [1]) without disrupting the colonywide volume flow rate, previous studies have shown that experimentally reducing colonywide volume flow rate but maintaining stolonal architecture also affect morphological development (Blackstone and Buss 1992,1993). Metabolic perturbations by application of 2,4-dinitrophenol (an uncoupler of oxidative phosphorylation) reduce the energy available for polyps to pump gastrovascular fluid (reduced $\Delta p$, in eq. [1]) and, hence, reduce volume flow rate. Similar reductions of volumetric rate were achieved by overfeeding, which presumably increased dynamic viscosity (increased $\mu$, in eq. [1]) or made the gastrovascular fluid non-Newtonian, through an increase in solute concentrations.

Such colonywide reductions in flow rate accelerated rates of polyp production and stolon branching in Podocoryne carnea, but the effects on Hydractinia varied depending on the morphology of the clone used. We observed that the placement of polyps on the stolonal mat, but not their rate of production, was affected by changing flow patterns through manipulations of stolonal architecture. These two results suggest that the signaling of genes involved in polyp formation, as well as processes mediating development of stolonal mat morphology, are regulated by hydrodynamic characteristics of flowing gastrovascular fluid. However, the results of the sheet-to-runner experiment suggest that although flow patterns are a determinant of morphological patterning of polyps, they are not the sole determinant. The distribution of polyps was affected similarly (relative to controls) either by severing the ring canal or by piercing epithelial mat tissues without severing any stolons. A continuous nerve net occurs throughout the stolonal mat (Müller 1964), and our results suggest that neural responses can also influence the sites of polyp formation. Nonetheless, changes in volume flow rate, locally or globally throughout a colony, have morphological effects that are consistent with the hypothesis that morphogenetic events are signaled on the basis of local physiological states. 
It is likely that severing stolons affects the physiology of colonies beyond that of altering gastrovascular flow. Severing stolons may alter metabolism associated with wounding, as in bryozoans (Harvell and Helling 1993), or may trigger the release of activating or inhibitory substances having morphogenetic consequences (Lange and Müller 1991). However, we contend that the morphological changes observed were attributable to changes in gastrovascular flow patterns for two reasons. First, the five "treated" colonies in the sheet-to-runner experiment that did not exhibit changes in stolonal architecture (yet presumably experienced the other "unknown" effects associated with the manipulation) did not change morphology. Moreover, three separate manipulations (treatment with 2,4dinitrophenol, overfeeding [Blackstone and Buss 1992, 1993], severing of stolons [this study]) that share the property of altering flow patterns but probably have different "unknown" effects similarly affect morphological development.

\section{Mechanisms Linking Physiology to Gene Expression}

The association between colony morphology and gastrovascular flow prompts hypotheses about the mechanism(s) that signal the expression of genes governing morphogenetic events. Presently, our experimental evidence is inadequate to support any hypothesized mechanism, but two alternatives merit exploration. Endothelial cells lining the lumen wall of stolons experience variation in (1) availability of metabolites via diffusion and (2) shear stress caused by gastrovascular flow. These two mechanisms are not necessarily exclusive alternatives; they could act in concert to determine fates of endothelial cells.

The delivery of metabolites to the surface of an endothelial cell lining the stolon lumen is a function of both forced convection of gastrovascular fluid and molecular diffusion (Patterson 1992a). Greater flow speeds occurring in largerdiameter stolons (Vogel 1981, 1992; LaBarbera 1990) result in a thinner diffusive boundary layer, thereby increasing the mass transfer of metabolites from the gastrovascular fluid to the endothelial cell surface (Patterson et al. 1991, 1992a, $1992 b$ ). Wider stolons, therefore, experience greater access to metabolites than narrower stolons.

Hydrodynamic shear stress at the lumen wall increases with the speed of flow through a stolon (Vogel 1981). Therefore, the lumen wall of stolons of larger diameter is subject to greater shear stress than that of stolons of smaller diameter because flow speeds in the former are greater for a given pressure drop. The presence of digested food particles in stolons may render the gastrovascular fluid non-Newtonian (i.e., shear thinning). The effects would be more pronounced in smaller-diameter stolons (i.e., dynamic viscosity of the gastrovascular fluid would decrease more compared with that in larger-diameter stolons), as occurs in mammalian circulatory systems (Vogel 1992). Since shear stress is proportional to dynamic viscosity, changes in the latter would alter shear stresses along the wall of the stolon lumen. The occurrence of a shear-thinning gastrovascular fluid would affect cells lining the walls of smaller-diameter stolons more than those of larger-diameter stolons by reducing shear stress signals more.

A precedent for the potential importance of shear stress for morphogenesis is provided by mammalian vascular systems. Mammalian vascular endothelial cells signal morphogenetic events based on shear stress gradients. In mammals, shear 
stresses associated with pulsatile flow (such as occurs in hydroid stolons) have a greater effect on cellular function than shear stresses associated with steady flow, and tissues lacking an endothelial cell layer show no response to shear stress (Frangos et al. 1985; Davies et al. 1986; Rubanyi et al. 1986; Resnick et al. 1993). Shear stress is known to stimulate phosphoinositide turnover, producing the second messengers inositol triphosphate (Ins1,4,5 $\mathrm{P}_{3}$ ) (Prasad et al. 1989; Nollert et al. 1990) and 1,2-diacylglycerol (DAG) (Berridge and Irvin 1989).

The findings in mammalian systems are particularly intriguing in light of what is known about hydroid pattern formation. For example, DAG has been shown to induce ectopic heads in Hydractinia and Hydra (Müller 1989). Moreover, Shenk et al. (1993) provide direct evidence of DAG-mediated Cnox-2 expression in Hydra; Cnox-2 is a HOM/HOX gene, the expression of which is correlated with axial pattern formation of polyps, and is the first homeobox known to be regulated in this fashion. While none of these facts is individually compelling, it is clearly feasible to design experiments directly addressing the mechanisms by which gastrovascular physiology regulates expression of pattern-forming genes.

\section{Consequences of Physiological Maintenance of Colony Form}

The malleability of colony form on the basis of local physiological state likely has pronounced ecological consequences with regard to the capacity of a colony to respond to changing ecological circumstance. However, morphological transitions in nature are probably asymmetric, at least in the case of Hydractinia where sheets are more likely to be transformed to runners than runners are to be transformed to sheets. In nature, any of a variety of environmental fluctuations or disturbances to a sheet colony (e.g., accidental severing of a stolon) will be likely to introduce local variation in circulation patterns within the gastrovascular system that, if maintained, will result in the development of peripheral stolons and a runner morphology. In contrast, the probability of losing all peripheral stolons and consequently reducing within-colony variation in flow needed to generate sheet forms is very small. Transformation of sheets to runners should increase the competitive ability of these colonies since competitive superiority is associated with the presence of peripheral stolons (Buss et al. 1984; Buss and Grosberg 1990). Such developmental plasticity may be beneficial to morphologically transformed colonies, particularly in populations where the instance of intraspecific competition is high, and may mask selection against the competitively inferior sheet genotypes, thus providing an additional mechanism maintaining heritable morphological variation in natural populations (see Yund 1991 for a general treatment of maintenance of morphological variation in hydractiniids).

While specific advantages (or disadvantages) attributable to the malleability of growth form will vary with ecological circumstance, our results also speak to a more general point. Clonal life cycles occur in many multicellular eukaryotes, including several invertebrate phyla, numerous algal and plant groups, and the majority of fungi. Morphological variation of Hydractinia symbiolongicarpus strains is representative of much of the diversity observed among clonal taxa, in that many of these groups characteristically exhibit analogous variation in the spacing and arrangement of ramets and stolons. Associated with this variation is 
a suite of correlated life-history traits (see, e.g., Buss 1979; Jackson 1979; Harper 1985). Our results bear on the claim that the correlation between colony morphology and life history is causal (Blackstone and Buss 1992), in that differing patterns of vascular connectivity will necessarily imply differing energetic costs. For example, in Hydractina, the length of stolon serviced per polyp will be greater in a runner than in a sheet; hence, the per-polyp maintenance costs will be greater in a runner, leaving less energy for reproduction. Vascular connectivity codetermines life history and morphology. The malleability of morphology implies a similar malleability in life history and a substantially more flexible response of clonal organisms to environmental variation than that which characterizes unitary organisms.

\section{ACKNOWLEDGMENTS}

We thank N. Blackstone, D. Bridge, P. Cartwright, M. Dick, D. Harvell, J. Kübler, M. LaBarbera, O. Mokady, P. Snow, and G. Wagner for critical comments on an early version of the manuscript. Later reviews by D. Brumbaugh, R. Grosberg, J. Kingsolver, M. Patterson, and A. Wagner substantially improved the quality of this article. S.R.D. would like to thank G. Chapman and A. Underwood for introducing him to analyses of circular data and N. Blackstone, A. Johnson, J. Kübler, and R. Vaisnys for numerous discussions of circulation and referral to manuscripts. J. Maisano and J. Taschner provided technical assistance. Support was provided by the National Science Foundation (OCE-93-15082).

\section{LITERATURE CITED}

Batschelet, E. 1981. Circular statistics in biology. Academic Press, London.

Berridge, M. J., and R. F. Irvin. 1989. Inositol phosphates and cell signalling. Nature (London) 341: $197-205$.

Berrill, N. J. 1949. The polymorphic transformations of Obelia. Quarterly Journal of Microscopic Science 90:235-254.

Blackstone, N. W., and L. W. Buss. 1991. Shape variation in hydractiniid hydroids. Biological Bulletin (Woods Hole) 180:394-405.

1992. Treatment with 2,4-dinitrophenol mimics ontogenetic and phylogenetic changes in a hydractiniid hydroid. Proceedings of the National Academy of Sciences of the USA 89: 4057-4061.

1993. Experimental heterochrony in hydractiniid hydroids: why mechanisms matter. Journal of Evolutionary Biology 6:307-327.

Blackstone, N. W., and P. O. Yund. 1989. Morphological variation in a colonial marine hydroid: a comparison of size-based and age-based heterochrony. Paleobiology 15:1-10.

Bozzaro, S. 1992. Dictyostelium: from unicellularity to multicellularity. Pages 137-149 in V. E. Russo, S. Brody, D. Cove, and S. Ottolenghi, eds. Development: the molecular genetic approach. Springer, Berlin.

Buss, L. W. 1979. Habitat selection, directional growth and spatial refuge: why colonial animals have more hiding places. Pages 459-497 in G. Larwood and B. R. Rosen, eds. Biology and systematics of colonial organisms. Systematics Association Special Vol. 11. Academic Press, London.

Buss, L. W., and N. W. Blackstone. 1991. An experimental exploration of Waddington's epigenetic landscape. Philosophical Transactions of the Royal Society of London B, Biological Sciences 332:49-58. 
Buss, L. W., and R. K. Grosberg. 1990. Morphogenetic basis for phenotypic differences in hydroid competitive behavior. Nature (London) 343:63-66.

Buss, L. W., and J. R. Vaisnys. 1993. Temperature stress induces dynamical chaos in a cnidarian gastrovascular system. Proceedings of the Royal Society of London B, Biological Sciences 252:39-41.

Buss, L. W., C. S. McFadden, and D. R. Keene. 1984. Biology of hydractiniid hydroids. II. Histocompatibility effector system/competitive mechanism mediated by nematocyst discharge. Biological Bulletin (Woods Hole) 167:131-158.

Conover, W. J. 1981. Practical nonparametric statistics. Wiley, New York.

Davies, P. F., A. Remuzzi, E. J. Gordon, C. Forbes Dewey, Jr., and M. A. Gimbrone, Jr. 1986. Turbulent fluid shear stress induces vascular endothelial cell turnover in vitro. Proceedings of the National Academy of Sciences of the USA 83:2114-2117.

Dring, M. J. 1984. Photoperiodism and phycology. Progress in Phycological Research 3:159-162.

Frangos, J. A., S. G. Eskin, L. V. McIntire, and C. L. Ives. 1985. Flow effects on prostacyclin production by cultured human endothelial cells. Science (Washington, D.C.) 227:1477-1479.

Gebhardt, M. D., and S. C. Stearns. 1988. Reaction norms for developmental time and weight at eclosion in Drosophila mercatorum. Journal of Evolutionary Biology 1:335-355.

Hale, L. J. 1960. Contractility and gastrovascular movements in the hydroid Clytia johnstonii. Quarterly Journal of Microscopic Science 101:339-350.

Harper, J. L. 1985. Modules, branches and the capture of resources. Pages 1-33 in J. B. C. Jackson, L. W. Buss, and R. E. Cook, eds. Population biology and evolution of clonal organisms. Yale University Press, New Haven, Conn.

Harvell, C. D. 1991. Coloniality and inducible polymorphism: the interaction of zooid and colony level control. American Naturalist 138:1-14.

1992. Inducible defenses and allocation shifts in a marine bryozoan. Ecology 73:1567-1576.

1994. The evolution of polymorphism in colonial invertebrates and social insects. Quarterly Review of Biology 69:155-185.

Harvell, C. D., and R. K. Grosberg. 1988. The timing of sexual maturity in clonal animals. Ecology 69:1855-1864.

Harvell, C. D., and R. Helling. 1993. Experimental induction of localized reproduction in a marine bryozoan. Biological Bulletin (Woods Hole) 184:286-295.

Jackson, J. B. C. 1979. Morphological strategies of sessile animals. Pages 499-555 in G. Larwood and B. R. Rosen, eds. Biology and systematics of colonial organisms. Systematics Association Special Vol. 11. Academic Press, London.

Karlson, A. G., and N. N. Marferin. 1984. Movements of gastrovascular fluid in the colony of the hydroid Dynamena pumila and some other species [in Russian]. Journal of General Biology 45:670-679.

Kemball, W. D., and C. Marshall. 1995. Clonal integration between parent and branch stolons in white clover: a developmental study. New Phytologist 129:513-521.

LaBarbera, M. 1990. Principles of design of fluid transport systems in zoology. Science (Washington, D.C.) 249:992-1000.

Lange, R. G., and W. A. Müller. 1991. SIF, a novel morphogenetic inducer in Hydrozoa. Developmental Biology 147:121-132.

Lovett-Doust, L. 1981. Population dynamics and local specialization in a clonal perennial (Ranunculus repens). I. The dynamics of ramets in contrasting habitats. Journal of Ecology 69:743-755.

Lüning, K. 1986. New frond formation in Laminaria hyperborea (Phaeophyta): a photoperiodic response. British Phycological Journal 21:269-273.

Marferin, N. N. 1985. The functioning of the pulsatory-peristaltic type transport system in colonial hydroids [in Russian]. Journal of General Biology 46:153-164.

Marshall, C. 1990. Source-sink relations of interconnected ramets. Pages 23-41 in J. van Groenendaal and $\mathrm{H}$. de Kroon, eds. Clonal growth in plants: regulation and function. Academic Publishing, The Hague.

McFadden, C. S., M. J. McFarland, and L. W. Buss. 1984. Biology of hydractiniid hydroids. I. Colony ontogeny in Hydractinia echinata (Flemming). Biological Bulletin (Woods Hole) 166: 54-67. 
Miles, J. S., C. D. Harvell, C. M. Griggs, and S. Eisner. 1995. Resource translocation in a marine bryozoan: quantification and visualization of ${ }^{14} \mathrm{C}$ and ${ }^{35} \mathrm{~S}$. Marine Biology 122:439-445.

Müller, W. A. 1964. Experimentelle Untersuchungen über Stockentwicklung, polypen Differzierung und Sexualchimären bei Hydractinia echinata. Roux Archiv Entwicklung 155:181-268. 1989. Diacylglycerol-induced multihead formation in Hydra. Development 105:309-316.

Nollert, M. U., S. G. Eskin, and L. V. McIntire. 1990. Shear stress increases inositol triphosphate levels in human endothelial cells. Biochemical and Biophysical Research Communications 170:281-287.

Patterson, M. R. 1992a. A chemical engineering view of cnidarian symbioses. American Zoologist 32:566-582.

1992b. A mass transfer explanation of metabolic scaling relations in some aquatic invertebrates and algae. Science (Washington, D.C.) 255:1421-1423.

Patterson, M. R., K. P. Sebens, and R. R. Olson. 1991. In situ measurements of flow effects on primary production and dark respiration in reef corals. Limnology and Oceanography 36: 936-948.

Prasad, A. R. S., R. M. Nerem, C. J. Schwartz, and E. A. Sprague. 1989. Stimulation of phosphoinositide hydrolysis in bovine aortic endothelial cells exposed to elevated shear stress. Journal Cellular Biology 109:313A.

Resnick, N., T. Collins, W. Atkinson, D. T. Bonthron, C. Forbes Dewey, Jr., and M. A. Gimbrone, Jr. 1993. Platelet-derived growth factor B chain promoter contains a cis-acting fluid shearstress-responsive element. Proceedings of the National Academy of Sciences of the USA 90:4591-4595.

Rubanyi, G. M., J. C. Romero, and P. M. Vanhoutte. 1986. Flow-induced release of endotheliumderived relaxing factor. American Journal of Physiology 250:H1145-H1149.

Schierwater, B., B. Piekos, and L. W. Buss. 1992. Hydroid stolonal contractions mediated by contractile vacuoles. Journal of Experimental Biology 162:1-21.

Shenk, M. A., H. R. Bode, and R. E. Steele. 1993. Expression of Cnox-2, a HOM/HOX homeobox gene in Hydra, is correlated with axial pattern formation. Development 117:657-667.

Sinervo, B. 1990. The evolution of maternal investment in lizards: an experimental and comparative analysis of egg size and its effects on offspring performance. Evolution 44:279-295.

Stearns, S. C. 1992. The evolution of life histories. Oxford University Press, Oxford.

Stearns, S. C., and J. Koella. 1986. The evolution of phenotypic plasticity in life-history traits: predictions for norms of reaction for age- and size-at-maturity. Evolution 40:893-913.

Thompson, J. D. 1991. Phenotypic plasticity as a component of evolutionary change. Trends in Ecology \& Evolution 6:246-249.

Underwood, A. J. 1981. Techniques of analysis of variance in experimental marine biology and ecology. Oceanography and Marine Biology Annual Review 19:513-605.

Vogel, S. 1981. Life in moving fluids. Princeton University Press, Princeton, N.J.

- 1988. Life's devices: the physical world of animals and plants. Princeton University Press, Princeton, N.J.

1992. Vital circuits: on pumps, pipes and the workings of circulatory systems. Oxford University Press, Oxford.

Yund, P. O. 1991. Natural selection on hydroid colony morphology by intraspecific competition. Evolution 45:1564-1573. 